Abstract

\title{
Turkish Medicinal Plants Used in Cancer Treatment and Evaluation of Plant Usage in the Oncology Clinic of the İstanbul University Faculty of Medicine ${ }^{\dagger}$
}

\author{
Büşra Teke and Emine Akalın Uruşak * \\ Faculty of Pharmacy, İstanbul University, Istanbul 34452, Turkey; busrateke1969@gmail.com \\ * Correspondence: akaline@istanbul.edu.tr; Tel.: +90-212-4400000 (ext. 13578) \\ + Presented at the 2nd International Conference on Natural Products for Cancer Prevention and Therapy, \\ Kayseri, Turkey, 8-11 November 2017.
}

Published: 16 November 2017

\begin{abstract}
Plants are used as complementary and protective agents in the treatment of simple diseases as well as the severe diseases such as cancer. The plants in this poster are naturally grown in Turkey. Priority to plant selection has been given to past from in vivo tests and clinical tests. The plants are divided into two classes first. The first section contains 3 plants that are effective in protecting against cancer. In the second section, the plants used in cancer treatment are described and these plants are divided into 6 parts. These parts are; Direct Anticancer Effect Plants (18 Plants), Plants That Increase Chemotherapy Effect (10 Plants), Plants That Reduce Drug Resistance (2 Plants), Plants That Reduce the Side Effect of Chemotherapy (4 Plants), Plants That Reduce the Side Effect of Radiotherapy (3 Plants) and Plants That Strengthen the Immun System (1 Plant). The information in the literature has been added in each section. Some of the plants which have been proved end-effective effects by in vivo and in vitro tests are presented to the market as drugs. One hundred (51 male and 49 female) cancer patients were interviewed one by one. The rate of herbal treatment use of the patients was found to be $26 \%$. Patients use the herbal treatment mainly to improve general health, to treat cancer, to reduce the side effects of drugs and to boost the immune system. One hundred (51 male and 49 female) cancer patients were interviewed one by one. While $76.92 \%$ of the respondents stated that they benefit from herbal remedies, $23.07 \%$ of them said that they did not benefit or suffer any damage. No serious side effects were reported among the participants.
\end{abstract}

Keywords: Turkey; medicinal plant; cancer; complementary; treatment

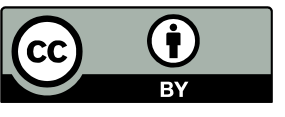

(C) 2017 by the authors. Licensee MDPI, Basel, Switzerland. This article is an open access article distributed under the terms and conditions of the Creative Commons Attribution (CC BY) license (http://creativecommons.org/licenses/by/4.0/). 